\title{
Possible Solutions to Foundation Phase Mathematics Difficulties
}

\author{
Maphetla M Machaba \\ Department of Early Childhood development \\ University of South Africa (Unisa) \\ machabmm@unisa.ac.za
}

Doi:10.5901/mjss.2013.v4n14p255

\begin{abstract}
This investigation emanates from the realization that Grade 3 children at schools in disadvantaged areas perform poorly in basic mathematics computations such as addition, subtraction, multiplication and division. The aim of the research was to establish the approaches teachers use when teaching mathematics computation. The qualitative approach, together with the research techniques commonly used with it, namely observation, interviews and document analysis was deemed appropriate for the investigation. The outcomes of the investigation revealed that the multilingual Grade 3 classes made it difficult to assist all children who experienced mathematics problems because teachers could not speak all the other languages that were not the language of learning Language of Learning Teaching (LOLT) of the school. Another obstacle that prohibited teachers from spending adequate time with children with mathematics problems was the time teachers were expected to spend on intervention programmes from the Department of Basic Education (DBE) aimed at improving schooling in general. Teachers could not make additional time that could afford children the opportunity of individual attention.
\end{abstract}

Keywords: intervention programmes mathematical difficulties, numerical knowledge and conceptual knowledge

\section{Introduction}

The previous chapter examined the literature and explained the theoretical perspective that could bear significance to this study. This chapter describes the various intervention programmes used in different countries to address mathematics difficulties experienced by children. The purpose of discussing intervention strategies is to gain insight into possible ways of assisting children who experience mathematics problems. Engaging in discourse on effective strategies will not deepen understanding about the programmes but will provide ideas that can be used to propose an intervention programme for teachers at the research schools.

Papatheodorou (2006:91) and Peterson (1987:5) allege that when a young child is found to have a difficulty or to be "at risk" of developmental difficulties, intervention should be initiated as early as possible. The early years in the learning of mathematics are regarded as a critical period, when children are most susceptible and responsive to learning experiences.

In addition, during the early years the initial patterns of learning and behaviour that set the pace for and influences the nature of all subsequent development, is established. Intelligence and other human capacities are not fixed at birth but rather, are shaped to some extent by environmental influences and through learning. When restricting conditions and other factors that render a child at risk for developing mathematics problems and learning are present in the early years, there are chances that the problems could become more severe, in the early years (Papatheodorou, 2006:91).

Early intervention programmes can make a significant difference in the developmental status of young children and can do so more rapidly than later remedial efforts after a child has entered elementary school. Parents need special assistance in establishing constructive patterns of parenting young children who are at risk and in providing adequate care, stimulation, and training for their children during the critical early years when basic developmental skills should be acquired.

\section{Literature review}

\subsection{Principles of effective practice in mathematics teaching}

According to Fuchs, Fuchs, Powell, Seethaler, Cirino and Fletcher (2008:79), approximately 5\% to 9\% of school children 
may be identified with mathematics difficulties (MD). This in spite of /the fact that poor mathematics skills are associated with life-long difficulties in the workplace and school (Fuchs et al., 2008:79). Some research illustrates how prevention activities at crèche or Grade 1 level can drastically improve mathematics performance. Fuchs and colleagues (2005) for example, identified 169 children in 141 classes as being "at risk" for mathematics difficulties based on their low initial performance. These children were subsequently randomly assigned either to a control group or to receive tutoring in small groups thrice per week for 16 weeks (Fuchs et al., 2008:80).

Results indicated that mathematics development across first grade was significant and much superior for the tutored group than for the control group on mathematical calculation, concepts, applications and story problems.

Furthermore, the incidence of children with a disability in mathematics was greatly reduced by the end of Grade 1; this reduction remained in the spring of Grade 2, one year after the end of tutoring (Fuchs et al., 2008:80).

The above illustrates that if mathematical problems can be identified at crèche or entry to school and intervention such as tutoring applied, the chances are that by the time children reach Grade 3 most of their mathematics problems will have been overcome.

This strengthens the notion that intensive remedial intervention is important. It also indicates the relevance and importance of pre-school education, which is unfortunately not a common phenomenon among children in the schools on which the researcher focused. It is important that the DoE should look into encouraging pre-school education or making it compulsory, especially in informal settlement areas.

\subsection{An early intervention strategy in literature and mathematics programme}

In 1997, the Scottish Office of Education [Intervention] Department (SOEID) decided to implement an early intervention strategy in literature and mathematics as part of a national programme to raise standards in the early stages of primary education in Scotland. This strategy targeted P1 to P3 stages and children from five to seven years old (Stobie, 2004:157). It is a prevention programme.

The programme involved in-service training and staff development on literacy and mathematics for P1 teachers. It emphasised the teaching of phonological awareness through concentrating on the first phoneme in a word and the remainder of the words, a book-rich environment and parent involvement. It also concentrated on a staff tutor to work with the schools involved in the programme and to lend support to teachers in improving approaches to literacy and mathematics. The programme also had to have qualified nursery nurses who had to work collaboratively in P1 classes in the schools. A lending and evaluation collection of resources for mathematics and literacy for schools is also involved in early intervention. Finally, there is provision of more resources for book corners for P1, P2 and P3 levels (Stobie, 2004:158).

The one dimension of this programme concerns populations who are about to undergo life transitions like entering school and who lack positive early learning experiences. These populations also lack positive early learning experiences and find school to be a challenging process in which they may meet failure (Stobie, 2004:158).

It is these kinds of children, on which the study concentrated. They stem from a "retarded" milieu, are poverty stricken and, most if not, all of them did not attend nursery school and thus they come to school with no prior experience of formal learning. Hence, school is viewed by these children as a place where they are likely to fail and consequently they enter school without any motivation. These children also lack experience (prior knowledge is retarded) in that they come from a poor environment, where for example, parents are illiterate, there are no books, televisions, and newspapers to stimulate them.

The aim of the programme was to identify aspects of programme delivery in the selected schools that had to do with good practice in connection with mathematics and literacy. Case-study methodology was used to examine the following variables:

- the use of staffing - including nursery nurses

- approaches to curriculum - including environment and parent engagement

- introduction of phonic sounds - recording children, and

- Parents' perspectives (Stobie, 2004:159).

The analysis included samples of documentation (school policies on early intervention, school development plans, etc.), class observation of interactions between children and teachers (nurse included), interviews with principals, class teachers, nursery nurses, class assistants, parents to children, and children and a questionnaire regarding literacy administered to the children involved (Stobie, 2004:159).

This analysis strategy is similar to the one used in this study even though the SOEID programme goes a little 
further than the one used in this study by involving the principals and nurses.

The findings reflected the importance of the increased staffing by nurses. The nurses and classroom assistants were considered as an important part of the programme. Their function was to strengthen teaching and to foster the children's interest in literacy and mathematics activities. They also successfully planned and recorded and assisted in identifying children at risk of failure.

Observation revealed that children in the first two years of study, where additional staffing was routinely used to create smaller teaching groups, were very responsive and engaged in their learning. Interviews with class teachers and principals showed that staff development opportunities were highly valued and that there was a continued need for ongoing staff development with regard to mathematics and literacy, especially classroom management and organisation together with planning and target setting. In-service training was regarded as very important, especially for new staff (Stobie, 2004:160).

In other words, this programme highlighted the fact that all staff members should work together in order to ensure the success of the programme. This is lacking in the schools in this study, where grade teachers seem to be on their own and intervention is only done at certain times for specific identified children, instead of there being an ongoing preventative strategy. The main disadvantage of this strategy was found to be a lack of staff to sustain the programme.

The teachers agreed that there was an increase in the levels of achievement as a result of an increase in the pace of children learning mathematics. This could also be attributed to staff development in the theoretical background of the strategy. This improvement was better recognised where there was a high degree of record-keeping and target setting (Stobie, 2004:161).

In the schools that participated in this research, the above mentioned were found to be lacking. It is vital that attention should be paid to these aspects of the strategy. Without proper record-keeping and target setting, progress will be slow. In some schools, children who experience difficulties are identified each year by class teachers instead of them being identified once and a record kept of their development through the various stages and targets set for them to achieve. In the schools in this research, the identification of children and the remedial work involved occurs on an ad hoc basis and does not lead to a permanent solution.

The focus group interviews and questionnaires indicated that parent involvement in classrooms and home support to children was uneven in the phases (grades). The study revealed that Grade 3 children received little help with reading and mathematics at home. The Grade 3 children also used the book corners in the classrooms (Stobie, 2004:161). Despite this, parental involvement was evident in participating schools. Home-school diaries were used and interviews with parents confirmed that these workshops helped parents to help their children at home.

However, some parents were not clear how to assist the children with numbers. Parental support seemed to decrease in Grade 3 compared to earlier grades (Stobie, 2004:162). Although parent involvement was low, it was better than that at the schools under investigation. This indicates that parents need to be encouraged to play a more active role in their children's education, especially at the lower grades, to render the child's transition to formal education easier.

The provision and use of resources, human and material, is important for the success of the programme. Initial and continued training for staff is needed for the success of the programme. Assessment needs to be built into the programme as well. The result of assessments, especially national assessments, should be fed back to the schools (Stobie, 2004:166). Doing this would ensure success.

This programme relies on all the role players pulling their weight in order to achieve success. The role of the teacher and the other staff is critical, for it is at this level of the programme that identification and remedial work is conducted. If properly carried out, the programme can go a long way in helping children. This kind of intervention, if adopted in South Africa, could contribute greatly to helping to remedy the mathematics problems encountered in South Africa. The programme was also applied among children from a poor economic background as prevailed in the schools where the researcher conducted this research.

\subsection{Oxford Mathematical Recovery Scheme}

Various studies have proved that significant numbers of people experience problems with mathematics. The Esmee Fairbian Charitable Trust is currently conducting a Mathematics Recovery scheme on a pilot basis with six and seven year old children in six First Schools in Oxford (Dowker, 2001:6).

The children involved have been identified by their teachers as experiencing problems with mathematics. The children are assessed on eight components of early mathematics. The children receive weekly individual intervention of half-an-hour a week on specific components in which they have problems. The remediation is carried out by classroom 
teachers recommended by Ann Dowker. The teachers are released from classroom teaching by the authorities for the intervention. Every child remains in the intervention programme for 30 weeks or until teachers are satisfied that the child no longer needs remediation. Periodically, new children are introduced to the project (Dowker, 2001:6).

The components that form the focus of the project include basic counting, use of written mathematical symbolism, place value, word problems, translation between concrete, verbal and numerical formats, derived fact strategies for calculations, estimation (mathematical) and memory for number facts (Dowker, 2001:6).

With regard to counting, children are made aware that the result of counting a set of items will not change even if you count them in a different order, but adding and subtracting items will change the number. They are taught addition by one, that is, children count a set of counters and are asked how many there will be if one or more counters are added, up to twenty. The same is done where children count items and are asked how many will remain if one is taken away. This is repeated down to zero. The children are also given practice in observing and predicting the results of these repeated additions and subtractions using counters as a form of intervention and asked questions like, "what is the number before six?" or "what is the number after six" (Dowker, 2001:7).

With regard to writing quantities as numerals, children are made to read aloud a set of single and two digit numbers. A similar set of numbers is then dictated for children to write. As a form of intervention, the children are made to practise reading and writing numbers. Those who experience problems in writing and reading two digit numbers are given a practice task in sorting objects into groups of ten and recording them, for example, 20, 30, 40, etcetera. This is carried out where there are extra units (Dowker, 2001:7).

Concerning place value, the children are asked to add tens to units $(30+2=32)$ and the ability to combine the two into one operation $(20+31=53)$. The children may also be made to print to the larger number in pairs of two digit numbers that differ with regard to the units, for example, 24 versus 27, or 37 versus 31. As intervention, children are shown how to add tens to units and tens to tens in various different forms (written, number line, picture, etc.) (Dowker, 2001:7).

Children who experience problems with solving word number problems are given addition and subtraction word problems which are discussed with them. The children are urged to use counters to represent the operations in the word problems and to write the sums numerically as a form of intervention (Dowker, 2001:8).

To address the problem regarding translation between concrete, verbal and numerical formats, children are given tasks of translating in all possible directions between written sums, operations with counters and word problems format for addition and subtraction. For instance, translating from verbal to numerical, children can be presented with a word problem such as, "Lethabo had seven bananas, and she ate three and is left with four". They are asked to write down the sum that goes with the story. Children are shown the same problems in different forms (Dowker, 2001:8).

One difficulty to mathematics that children experience is with regard to the lack of ability to derive and predict unknown numerical facts from known facts. Children are given the addition and subtraction Principles Test developed by Dowker $(1995,1998)$. In this particular test, children are provided with an answer to a problem and then asked to solve another problem that could be resolved quickly by using an appropriate mathematical principle; for example, they may be shown the sum, $33+44=77$, and then asked to do the following sums, $33+45$ or $23+44$. The children are asked whether the "top sum" helps them to do the "bottom sum" and why. If children fail to solve these problems, the strategies are demonstrated again to them using single digit addition and subtraction problems, with the help of objects and a number line (Dowker, 2001:8).

Some children do not have the ability to estimate an approximate answer to a mathematical problem. They also cannot evaluate the reasonableness of a mathematical estimate. To assess and remediate this, children are given a task developed by Dowker (1996). They are presented with a number of problems with different levels of complexity and with estimates already made for the problem by imaginary characters. For example, Sello and Mathapelo estimate on a five point scale ranging from "very good" to "very silly" and children are asked to suggest "good guesses" from these problems themselves. Addition and subtraction problems varying in degree of difficulty from those that a child may readily calculate mentally, to those just beyond the child's capacity to calculate, and to those difficult to solve. They are urged to provide reasons for their answers (Dowker, 2001:8-9).

The ability to memorise number facts is a problem for some children. This is an important factor to be able to understand mathematics. In the study, this skill is assessed through the Russell and Ginsburg (1981) Number Fact Test (Dowker, 2001:9). In the intervention, children are given some elementary addition and subtraction facts such as, 3+3=6, $5+5=10$. The same sums are given repeatedly in the sessions. Children also play "number games" that reinforce knowledge of number facts (Dowker, 2001:9).

The evaluation of the project is performed by giving the children in the project as well as their classmates and children from other schools the following Standardised Mathematics Tests: British Abilities scales Basic Number Skills 
Gubfert (1995 revision) together with the WISC arithmetic subtest. The first places greater emphasis on computation abilities and the second on arithmetic reasoning. The tests are carried out at intervals of six months (Dowker, 2001:9).

The project and its evaluation are still at an early stage. Nevertheless, the results have thus far been encouraging. "The mean standard score on the BAS Basic Number Skills Subtest were 93.52 (standard deviation 12.98) initially, and 97.94 (standard deviation 2.41) after six months. Wilcoxon tests showed both improvements to be highly significant. The re-testing and evaluation is intended to be carried out over a period of three years to assess if the gains made in the study are preserved over a longer term (Dowker, 2001:9).

The children involved in this particular project in the six First Schools in Oxford are of the same age and grades as those in this research. They were identified by their teachers as experiencing difficulties to mathematics similar to those identified in the researcher's study. These identified children, in the Oxford project are then given the forms of remediation described above, whereas those identified in the researcher's study are left for the teachers, parents and district officials of the DoE to help them. The intervention in South African schools also takes a very short time and there is no standardised remediation. Although the Oxford project is relatively new, the various forms of its remediation are very much better than the one offered in our schools. It also emphasises specific skills development in components similar to those that children in the schools the researcher visited and which also experience problems in this regard. Hence, following the remediation used in the Oxford project would be very viable in the South African situation, as the project is already showing signs of very good effectiveness given the initial findings.

\subsection{Intervention programme focusing on basic numerical knowledge and conceptual knowledge}

According to Copley (1999), informal handling of mathematical procedures and concepts result in better learning effects than formal school mathematical teaching. They allege that this might be because informal learning is linked to everyday activities and so it is meaningful, while formal learning is rather abstract, it happens in isolation, not in a particular context, and at times even requires the children to suppress their informal numerical knowledge (Kaufmann, Handl and Thony, 2003:565). This suggests that children find it easier to learn mathematical concepts informally than formally.

The aim of the study was to measure the effect of a mathematics intervention programme specifically designed to tap arithmetic and numerical problem areas of children with mathematical learning disabilities (MLD) (Kaufmann, Handl and Thony, 2003:565). The results indicate that many poor calculators and children with MLD have poor or faulty conceptual knowledge.

With regard to intervention, preliminary results of a longitudinal study by Dowker (2000) indicated that children with dyscalculia benefit from mathematics interventions that include problem areas such as counting, use of place value, translation between concrete, verbal and numerical formats and so on (Kaufmann, Handl and Thony, 2003:565). This implies the integration of concrete and abstract counting skills, in other words, the use of formal and informal learning activities.

The experimental groups consisted of six children with developmental dyscalculia. The diagnosis was confirmed by a school psychologist. All participants were recruited from an experimental class for children with isolated learning disabilities. A group of eighteen children without learning disabilities and with average intellectual abilities served as a control group. All children were in third grade and right handed. The mean age of the experimental group was 9.6 years $(S D=0.4)$ and that of the control group was 9.4 years $(S D=0.4)$ (Kaufmann, Handl and Thony, 2003:565-566).

All the participants were subjected to a comprehensive test of number processing and calculation skills. The calculation battery was assigned to test all components of basic numerical, procedural and conceptual knowledge. The battery quantified performance differences between control and experimental group participants before and after intervention. It also evaluated the efficiency of the intervention programme by means of reassessing the children at the conclusion of the intervention (Kaufmann, Handl and Thony, 2003:566).

The intervention programme was conducted among the second and third grades, three times a week for about six weeks. Each session lasted twenty-five minutes. The intervention schedule consisted of semi-hierarchically organised modules aimed at establishing basic conceptual and numerical knowledge by guiding the children's understanding from the concrete to the abstract meanings of numerals. The learning material was also, where possible, offered in a game like fashion. Every module incorporated explicit teaching of conceptual knowledge by making the children familiar with the inversion of problems of the calculations they have to work on by either making up stories related to their calculation and estimating an appropriate result or by having them reconstruct calculations using concrete objects (Kaufmann, Handl and Thony, 2003:566).

The data analysis looked at basic numerical knowledge like counting sequences, thermometer, dot enumeration, 
number bisection and number comparison; arithmetic fact knowledge, like basic number facts; procedural knowledge such as solving complicated written calculations; and conceptual knowledge like arithmetic principles. Non-parametric statistical procedures were used because of non-normal data distribution. The control group outperformed the experimental group on all components of number processing and arithmetic. At the conclusion of the intervention programme, these performance differences among groups were still significant even though slightly attenuated with respect to numerical fact retrieval, conceptual knowledge and procedural knowledge. Only tasks that tapped basic numerical knowledge stopped showing group differences at Time 2 for mean percentages of correct responses.

With regard to basic reaction time (RT) effects, only the control group showed subitising in dot enumeration and distance effects in number comparisons in both Time 1 and Time 2. The experimental group however showed subitising abilities only at Time 2 and displayed prolonged latencies in enumerating small dot arrays at Time 1 . Surprisingly, the experimental group demonstrated a preserved distance effect at Time 1, but just partial at Time 2 (Kaufmann, Handl and Thony, 2003:567).

With regard to more detailed analysis of the results, both groups demonstrated significant changes with regard to arithmetical fact knowledge and procedural knowledge. For performance knowledge, the score increase was higher for the control group, and only approached significance for the experimental group (Kaufmann, Handl and Thony, 2003: 567568). Finally, when calculating a composite score that included all numerical tasks, the intervention effects were found to be significant in the experimental group. Performance changes over time in the control group were not significant (Kaufmann, Handl and Thony, 2003:568). Teachers and parents in the experimental group demonstrated an obvious learning transfer with regard to their attitude towards mathematics and their level of achievement (Kaufmann, Handl and Thony, 2003:569).

The above results demonstrate the importance of basic numerical knowledge and conceptual knowledge for children to successfully acquire and apply calculation skills (Dowker, 2000).

\subsection{An early childhood intervention programme and the long-term outcomes for children}

Reynolds, Mann, Miedel and Smokowski (1997) identified a number of assumptions believed to guide early childhood intervention programmes. They firstly assume that the underlying conditions of poverty affect the child's development and are related to problems including school underachievement and delinquency. Secondly, they assume that educational and social enrichment can address some of these disadvantages. Thirdly, they claim that the child will experience early childhood education intervention (Martin, 2010:259-260).

There is scholarly evidence that in the United States, the early childhood intervention programme Head Start was successful in the early years. This programme aimed to improve the life chances of children through pre-school education. This programme was copied by the Bernard Van Leer Foundation of Holland and the Department of Education. The project was based in an area where most males were unemployed, part time work among females was common, and there was a very low level of parent education (Martin, 2010:260). (The conditions described there are almost similar to the ones prevailing where this study was conducted).

The project was conducted at Rutland Street Junior Primary School and Preschool. It was specifically established for children of three to five years old to improve their cognitive skills in preparation for their entrance to school. The project was influenced by Piaget's principles of development with specific stress on school readiness (Martin, 2010:260).

The first evaluation of the programme established that the children made good progress while attending the preschool centre, but the progress faded at primary school. This is in line with findings of other similar studies (Martin, 2010:260).

The research methods used for evaluation involved "a quasi-experimental design with two groups, the experimental group (programme participants) and the control group (judged equivalent to the experimental group but who did not participate in the pre-school programme). At the end of the pre-school period, the evaluation found great improvement in the children's performance on tests of scholastic ability, knowledge of numerical concepts and vocabulary, among others (Martin, 2010:261). Nonetheless, after three years, subsequent tests found that the level of scholastic achievement had deteriorated and participants fell under the achievements of the standard population, but above that of the control group. The findings were similar to those for the Head Start programme in the United States.

In a follow up study, the work experience and aspects of attitudes, leisure activities and social deviance, and the educational careers of the control group and the experimental group were measured and compared at the age of sixteen for the experimental group. The latter group reported that a high number of them received encouragement from their homes to go to the next level. Importantly, $9.6 \%$ of the experimental group progressed to the Senior Cycle compared with 
none of the control group. More significantly, the study found that a "lack of success at primary level was an important predictor of early school leaving" and that the experimental group (30.5\%) was three times more likely than the control group (11.8\%) to take the Intermediate Certificate Level (15 to 16 years).

The research aims to establish the intervention programmes that looked into when supporting children who experience mathematical computations. It also aims to establish how teachers resolve the problem with the aim of developing a support programme for foundation phase teachers.

\section{Research methodology}

The qualitative approach was used in this study to explore the views of grade three teachers regarding the approaches they use in teaching and learning of mathematics computation. We opted for this approach as it allows researchers to gain insight into the inner experience of participants, to determine how meanings are formed through culture, and to discover rather than test variables (White, 2005:81; Corbin \& Strauss, 2008:12). To collect data we used semi- structured interview as it helped to explain in detail what approaches teachers use when they teach computations in mathematics. For the purpose of this paper, we interviewed and observed five teachers from five different schools. The interviews were held during school time and lasted approximately 1-1/1/2 minutes. We conducted individual face-to-face interviews and did the observations with all the five teachers.

\section{Findings and discussions}

In some schools the School Base Support Team (SBST) exists only in name. An investigation of the team involved, demonstrated that in most schools the type of intervention given to the children does not improve their performance. For example, in most schools Grade 3 children are given Grade 1 work as an intervention. This is only part of the solution to the problem as the intervention leaves out the Grade 2 work. The child therefore would continue to have this gap (Grade 2 work) unfilled in his or her development and numerical understanding.

\section{Conclusions}

Continued research is needed to investigate mathematics intervention for struggling children: intervention that consists of the critical features of instructional design, including sufficient time for children to learn early mathematics concepts and operations (Bryant, Bryant, Roberts, Porterfield and Gersten 2011:9).

\section{References}

Bryant, D. P., Roberts, G., Bryant, B. R., and DiAndreth- Elkins, L. (2011). Tier 2 for K - 2 early numeracy number sense interventions for kindergarten and first - grade students with mathematics difficulties. In Gersten and B. Newman - Gonchar (Eds), Rtl mathematics book (pp $65-83$ ). Baltimore, MD: Brookes.

Corbin, J. and Strauss, A. (2008). Basics to qualitative research $3^{\text {rd }}(E d)$ USA: Library of Congress Cataloguing- in- Publication Data.

Copley, J. (Editor). (1999). Mathematics in early years. Reston, VA: National Council of Teachers of Mathematics.

Dowker, A.D. (2001). Numeracy recovery: a pilot scheme for early intervention with young children with numeracy difficulties. Vol. 16, No 1, 6-10.

Dowker, A., Hannington, J., and Matthew, S. (2000). Numeracy recovery: A pilot scheme: Early intervention for young children with numeracy difficulties. [Online] Available: www.tirp.org/pub/acadpub/Dowker2000.pdf.

Fuchs, L.S., Fuchs, D., Powell, S.R, Seethaler, P.M., Cirino, P.T., and Fletcher, J.M. (2008). Intensive intervention for students with mathematics disabilities: Seven principle of effective practice. Learning Disabilities Quarterly, 31.

Ginsburg, H. (1977). Children's Arithmetic: the learning process. New York N Y: D.

Kaufmann, L., Handl, P., and Thony, B. (2003). Evaluation of a numeracy intervention Program focusing on basic numerical knowledge and conceptual knowledge. 36 (6), 564-573.

Martin, W., Strother, S. Beglau, M., Bates, L., Reitzes, T., and Culp, M. (2010). Connecting instructional technology professional development to teacher and student outcomes. Journal of Research on Technology in Education, 43(1), 53-74.

Papatheodorou, T. (2006). Behaviour barriers in the early years. New York: Library Cataloguing in Publication Data.

Stobie, I., Boyle, J., Woolfson, L., Truswell, E., and Connaughton, N. (2004). Quality indicators for effective early intervention in literacy and numeracy. International Journal of Early Years Education, 12(2),

Peterson, N.L. (1987). Early intervention for handicapped and at risk child's. United States of America: Library of congress cataloguingin-Publication Data.

White, C.J. (2005). Research: a practical guide. Pretoria. Ithuthuko Investment (Publishing). 
